\section{Correspondence}

https://doi.org/10.11646/zootaxa.5047.1.10

http://zoobank.org/urn:1sid:zoobank.org:pub:9F53FFE7-15EA-4897-B71E-120C625502BE

\title{
The head of Cephalozygoptera (Odonata)
}

\author{
S. BRUCE ARCHIBALD ${ }^{1,2,3 *} \&$ ROBERT A. CANNINGS ${ }^{3,4}$ \\ ${ }^{1}$ Department of Biological Sciences, Simon Fraser University, 8888 University Drive, Burnaby, British Columbia, V5A 1S6, Canada \\ ${ }^{2}$ Museum of Comparative Zoology, 26 Oxford Street, Cambridge, Massachusetts, 02138, United States of America \\ ${ }^{3}$ Royal British Columbia Museum, 675 Belleville Street, Victoria, British Columbia, V8W 9W2, Canada

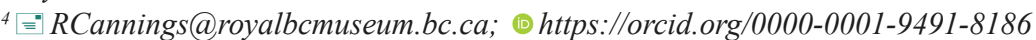 \\ "Corresponding author."sba48@sfu.ca; @ https://orcid.org/0000-0002-4397-2497
}

Archibald et al. (2021) proposed the Cephalozygoptera, a new suborder of Odonata. Its members resemble zygopterans in many ways, but differ most importantly by their distinctive head morphology. The suborder is comprised of the extinct families Dysagrionidae and Sieblosiidae, both of which had been previously considered members of the Zygoptera or probably so, with various authors expressing reservations, suggesting that they might belong to an undefined, extinct suborder (e.g., Garrouste \& Nel 2015). Archibald et al. (2021) also erected the family Whetwhetaksidae, tentatively in the Cephalozygoptera.

Nel \& Zheng (2021) challenged the existence of the Cephalozygoptera, stating that its defining head morphology is an artefact, distorted from a zygopteran shape during fossilization. They supported this claim by comparing the holotype of Lestes ceresti Nel \& Papazian (Lestidae) from the Oligocene of France and an undescribed odonate from the Paleocene of Tibet that they classify as a zygopteran with the head of Stenolestes falloti (Théobald) (Sieblosiidae) from the Oligocene of France. They claim that the $L$. ceresti and Tibetan zygopteran heads have a cephalozygopteran shape, not differing substantially from the $S$. falloti head; therefore, their shapes must be the products of distortion and the Cephalozygoptera is invalid. Their argument is based on comparative measurements of the head of the L. ceresti specimen, particularly of its compound eyes, which they describe as "adpressed to the head, with their posterolateral corners acutely protruding posteriorly" (page 166).

Its compound eyes are, however, completely absent (Fig. 1), presumably lost by post-mortem, pre-diagenetic damage (e.g., from decay, transport buffeting, weather, scavenging). Following their incorrect understanding of its head morphology, all of the measurements that they present are incorrect. The wide distance between the absent compound eyes and its short, transversely extended shape agree with the Zygoptera, not Cephalozygoptera. Three legs obscure much of the anterior of the head, but its posterior is clearly preserved and is deeply indented as in some Zygoptera and is more or less prominent in Lestes Leach species. We did not examine the undescribed Tibetan specimen, but the photograph of Nel \& Zheng (their Fig. 2B) indicates a zygopteran head for the same reasons.

The head of the $S$. falloti specimen to which Nel \& Zheng (2021, their Fig. 2A) compare those of the L. ceresti and Tibetan fossils is practically uninterpretable by poor preservation (our Fig. 2A), not useful for comparison, and the measurements that they present of its elements are unreliable. A fossil of its congener Stenolestes Scudder cf. fischeri Nel (specimen described by Nel et al. 1997), also in the Muséum National d'Histoire Naturelle collections, is much better preserved and is informative (Fig. 2B). Its head is in perfect concordance with the diagnosis of Cephalozygoptera: 1, its width across the compound eyes is a little more than twice the length from the anterior margin of the antefrons to the posterior of the occiput (Zygoptera: usually about three to five times wider); and it bears compound eyes that are: 2, adpressed to the head (Zygoptera: bulging outward), and; 3, separated by about one eye's width dorsally (Zygoptera: usually at least twice eye's width). This head is well preserved in three dimensions and shows no distortion, nor does its body or wing.

Nel \& Zheng (2021) ruled out post-mortem, pre-diagenetic damage to uniformly modify the heads - and only the heads - of all fossils assigned to the Cephalozygoptera, specifying that this distortion occurs "during their fossilization" (2021, page 166), i.e., is diagenetic distortion from geologic shear forces after the insect enters the substrate. This distorts the whole fossil and all other fossils in these beds (Fig. 3). The thoraces, wings, and all other parts of all Cephalozygoptera fossils with heads that we have examined appear unaltered. For a head to be distorted in this way would require one force to extend it and a separate force narrowing the space between the eyes without narrowing the eyes themselves, neither acting at any oblique angle. They did not propose what force(s) might act in this way. 


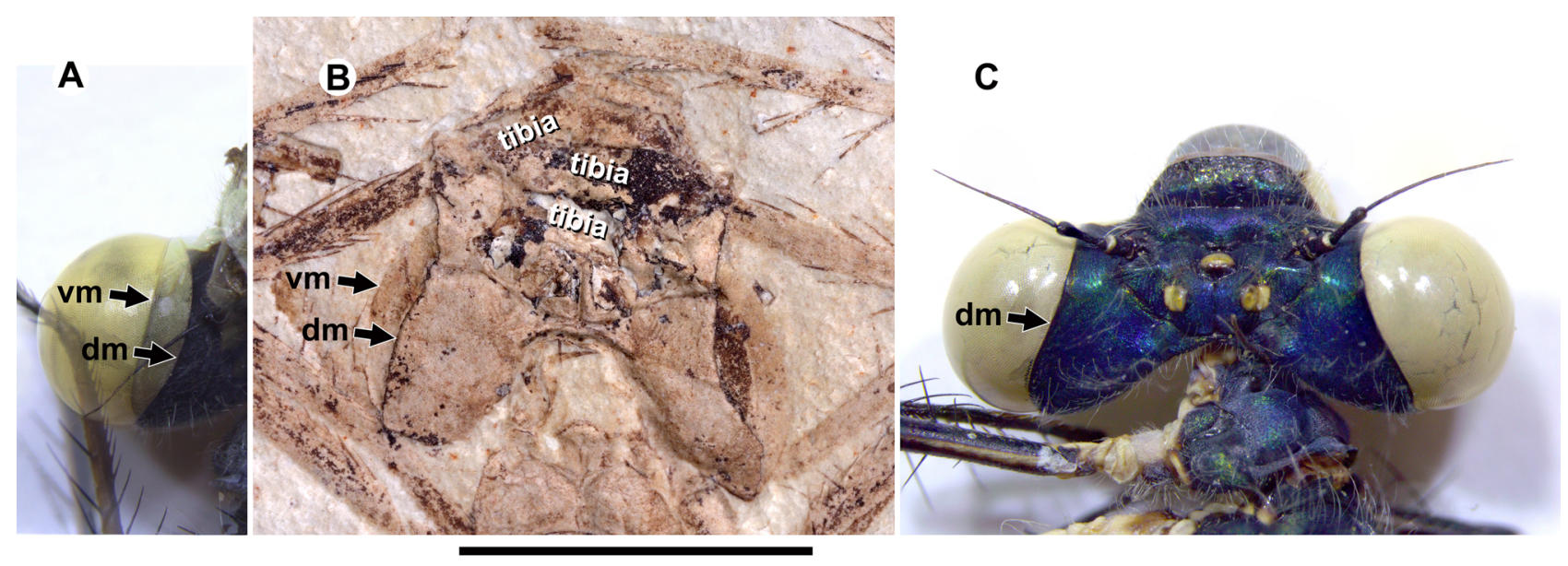

FIGURE 1. The heads of: A, the extant Lestes disjunctus Selys, a dorsal view superimposed over an aligned ventral view at $50 \%$ opacity showing the "dm" = dorsal and "vm" = ventral margin of the compound eye; B, the Lestes ceresti holotype MNHN. F.R07445 showing that the compound eyes are missing; C, the extant Lestes dryas Kirby in dorsal view, dorsal margin of the compound eye indicated. (B) is an extract from a reflectance transformation imaging (RTI) file (Cultural Heritage Imaging 2012), available upon request; $A$ and $C$ are digital photographs of specimens in the collections of the Royal British Columbia Museum (Victoria, BC, Canada). Scale bar $=3 \mathrm{~mm}$.

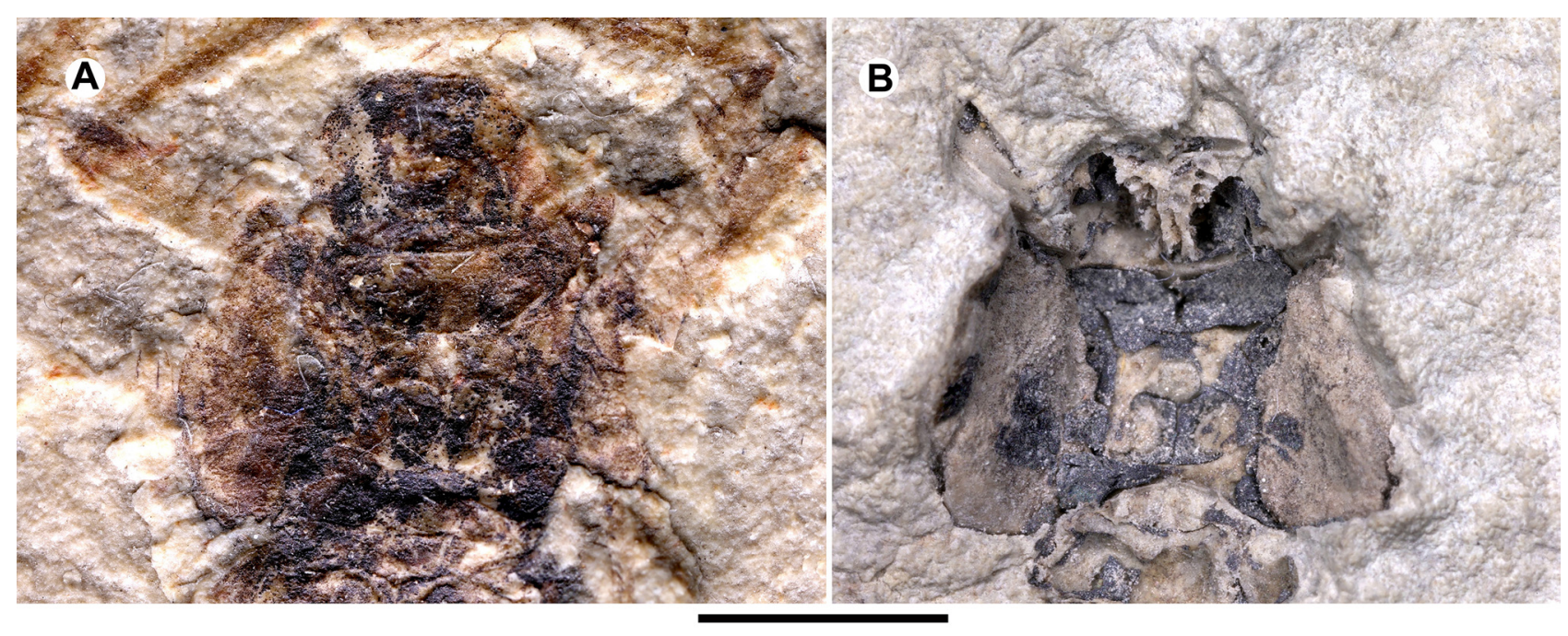

FIGURE 2. The heads of Stenolestes (Sieblosiidae): A, the S. falloti holotype MNHN.F.B24507 and; B, S. cf. fischeri MNHNF-B.47288. Both images are extracts from RTI files. Scale bar $=3 \mathrm{~mm}$.

We further examined five heads of Dysagrion fredericii Scudder (Dysagrionidae) (Fig. 4). They vary by pre-diagenetic damage, but all bear a consistent cephalozygopteran shape.

Zhang (1992: page 376) described the head of Congqingia rhora Zhang (Dysagrionidae) as nearly semicircular with large eyes separated by less than their width, not transversely elongate with eyes "as lateral swellings" and concluded that it is not a zygopteran. The distinctive damselfly head shape is clearly preserved as such in another fossil from these beds that "clearly shows a large transverse head, obviously wider than long, with eyes strongly projecting from the sides of the head and almost stalked ..." (page 380). He stated that fossils in this deposit are not distorted.

Garrouste \& Nel (2015) described the only specimen of Petrolestes hendersoni Cockerell (Dysagrionidae) with a head. They reported its compound eyes as $3.0 \mathrm{~mm}$ wide and $2.4 \mathrm{~mm}$ apart, i.e., separated by less than the width of one, and the head as $3.6 \mathrm{~mm}$ long and $5.2 \mathrm{~mm}$ wide, i.e., width about 1.4 times it's length, far less than in Zygoptera. From their figure 4, the compound eyes are adpressed to the head. They wrote that the head "appears not as transverse as in a Zygoptera" (page 359) but stated that this could be from compression, citing Lestes from the Oligocene of France to justify their conclusion. Aside from head shape, they concluded that its thoracic skewedness and short leg spines indicate that it and Congqingia Zhang and Dysagrion Scudder might not belong to the Zygoptera. 


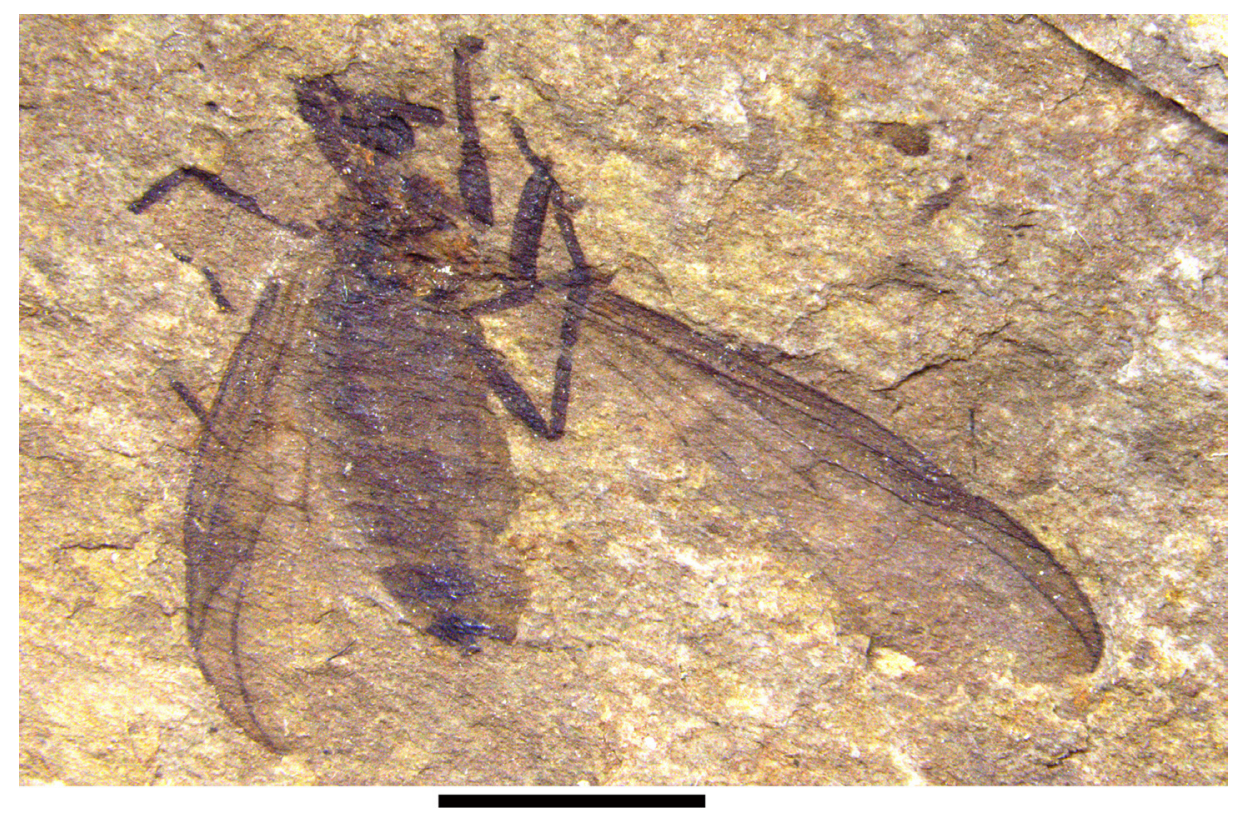

FIGURE 3. Plecia Hardy (Diptera, Bibionidae) (PMF.2019.0685.001) from the Allenby Formation (BC, Canada) uniformly altered by diagenetic distortion. Scale bar $=4 \mathrm{~mm}$.
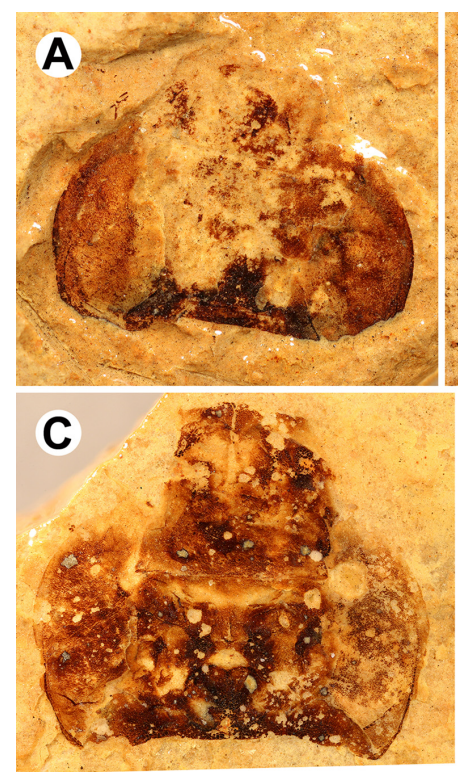
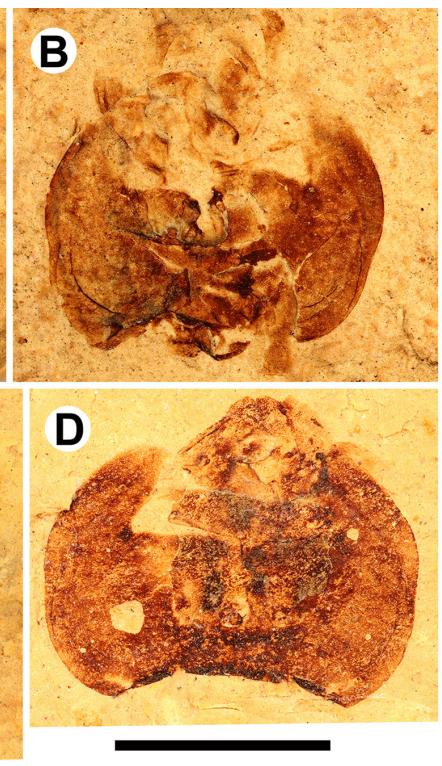

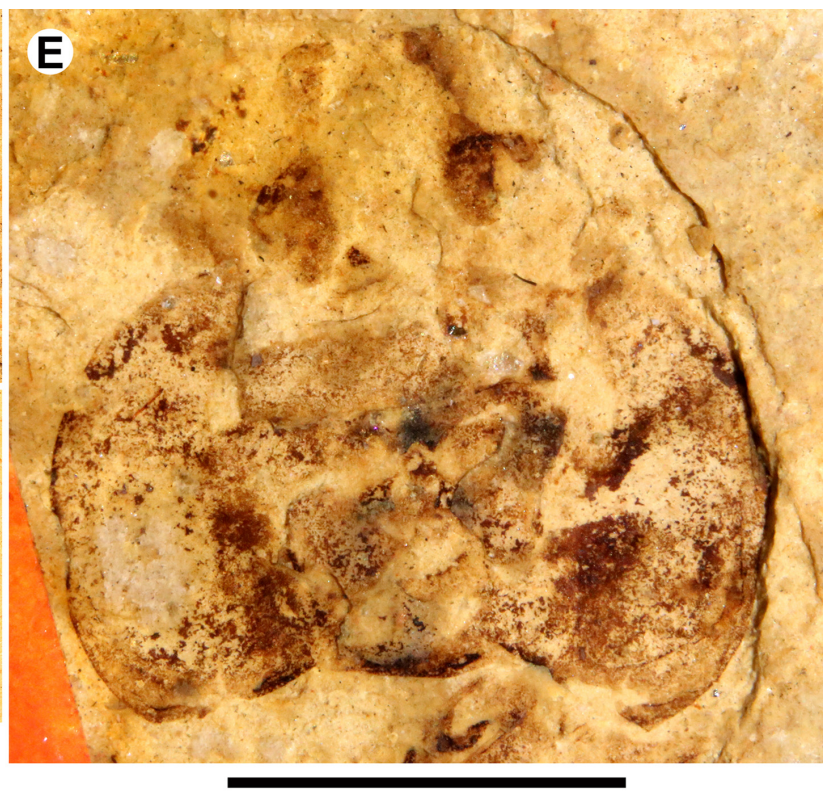

FIGURE 4. Heads of Dysagrion fredericii (Dysagrionidae) in the collections of the Museum of Comparative Zoology (Cambridge, MA, USA). A, MCZ:Ent:PALE-390; B, MCZ:Ent:PALE-4126; C, MCZ:Ent:PALE-385; D, MCZ:Ent:PALE-384; and E, MCZ:Ent:PALE-383. Scale bars (A-D and E) = $3 \mathrm{~mm}$. Scudder (1890) published a drawing of MCZ:Ent:PALE-383 (plate 6, Fig. 2, his number 4183) (and see Archibald et al. 2021, Fig. 10Q), and a drawing of MCZ:Ent:PALE-385 (plate 6, Fig. 10, his number 4179) (see Archibald et al. 2021, Fig. 10P).

Nel \& Zheng (2021) mention Eodysphaea magnifica Bechly et al., but we have not examined its specimen. Other occurrences with heads were discussed and illustrated by Archibald et al. (2021): Dysagrionidae: Phenacolestes parallelus Cockerell, Okanopteryx macabeensis Archibald \& Cannings, Okanopteryx fraseri Archibald \& Cannings, Okanagrion beardi Archibald \& Cannings; Sieblosiidae: Sieblosia jucunda (Hagen) (revised by Nel 1986); and a specimen designated Cephalozygoptera incertae sedis. 


\section{Conclusions}

We know of no force acting before or during diagenesis that might change the conservative zygopteran head shape to the diagnostic Cephalozygoptera shape. We conclude that the evidence from the specimens discussed by Nel \& Zheng (2021), and those further examined and discussed here and by Archibald et al. (2021) supports the proposal that the head shape ascribed to the Cephalozygoptera by Archibald et al. (2021) is their actual shape, and that the Cephalozygoptera is a valid taxon.

Note: We maintain that the Cretaceous genera Palaeodysagrion Zheng et al., Electrodysagrion Zheng et al., and Burmadysagrion Zheng et al. are not members of the Dysagrionidae and that the Paleocene genus Valerea Garrouste et al. is tentatively a member of the Dysagrionidae for reasons given by Archibald et al. (2021, pages 20 and 42).

\section{Acknowledgements}

We thank Olivier Béthoux and Gaëlle Doitteau (Muséum National d'Histoire Naturelle, Paris) for photographs and RTI files of the L. ceresti, S. falloti and S. cf. fischeri specimens; Whit Farnum and Crystal Maier (Museum of Comparative Zoology, Cambridge, MA) for photographs of the D. fredericii heads; Joel Gibson (Royal BC Museum, Victoria, BC, Canada) for loan of Lestes disjunctus and Lestes dryas specimens; Kathy Simpkins (Princeton and District Museum and Archives, Princeton, BC, Canada) for loan of the Plecia fossil; and Marlow Pellatt (Parks Canada, Vancouver, BC, Canada) for use of the microscope/digital camera in his laboratory. SBA thanks Rolf Mathewes (Simon Fraser University, Burnaby, BC, Canada) for facilitating research. This work benefited from a grant of the French state managed by the Agence nationale de la Recherche via the program "Investissements d'avenir" (ANR-11-INBS-0004-RECOLNAT).

\section{Literature cited}

Archibald, S.B., Cannings, R.A., Erickson, R.J., Bybee, S.M. \& Mathewes, R.W. (2021) The Cephalozygoptera, a new, extinct suborder of Odonata with new taxa from the early Eocene Okanagan Highlands, western North America. Zootaxa, 4934 (1), 001-133. https://doi.org/10.11646/zootaxa.4934.1.1

Cultural Heritage Imaging. (2012) http://culturalheritageimaging.org/Technologies/RTI/ (accessed 1 July 2021)

Garrouste, R. \& Nel, A. (2015) New Eocene damselflies and first Cenozoic damsel-dragonfly of the isophlebiopteran lineage (Insecta: Odonata). Zootaxa, 4028 (3), 354-366. https://doi.org/10.11646/zootaxa.4028.3.2

Nel, A. (1986) Révision du genre cénozoïque Stenolestes Scudder, 1895. Description de deux espèces Nouvelles (Insecta, Odonata, Lestidae). Bulletin du Muséum National d'Histoire Naturelle, Section C, Sciences de la terre, paléontologie, géologie, minéralogie, 8, 447-461.

Nel, A., Martínez-Delclòs, X., Papier, F. \& Oudard, J. (1997) New Tertiary fossil Odonata from France (Sieblosiidae, Lestidae, Coenagrionidae, Megapodagrionidae, Libellulidae). Deutsche Entomologische Zeitschrift, 44, 231-258. [https://onlinelibrary.wiley.com/doi/10.1002/mmnd.19970440210]

Nel, A. \& Zheng, D. (2021) The recently proposed odonatan 'suborder' Cephalozygoptera: fact or fiction. Palaeoentomology, 004 (2), 165-170. https://doi.org/10.11646/palaeoentomology.4.2.5

Scudder, S.H. (1890) The Tertiary insects of North America. Report of the United States Geological Survey of the Territories, $13,1-734,28$ pls. https://doi.org/10.5962/bhl.title.44698

Zhang, J.-F. (1992) Congqingia rhora gen. nov., spec. nov.- - a new dragonfly from the Upper Jurassic of eastern China (Anisozygoptera, Congquingiidae fam. nov.). Odonatologica, 21, 375-383. 